\title{
MIXED GROUP HIKERS OPTIMAL RESTING PLACE LOCATION ALONG TRAILS. TEST AREA AT LACU-ROSU REGION (ROMANIA)
}

\author{
Zsolt MAGYARI-SÁSKA'1, Ștefan DOMBAY ${ }^{1}$
}

DOI: 10.21163/GT_2016.112.07

\begin{abstract}
:
Hiking can bring together different people with different fitness level. To not to depart too much from each other resting places should be introduced. In some cases it's important to know the optimal locations of these places as they can be arranged with benches and tables. Our research focuses on developing a parameterized algorithm which can predict the optimal places of these resting locations. The developed algorithm was implemented in Python and used in QGIS for analyzing five important tourist trails in Lacu-Rosu region. Combining all possible fitness level pairs an inverse weighted method was used to locate the most important places which are suitable for arranged resting locations.
\end{abstract}

Key-words: trails, hiking, resting location, QGIS, Python, Lacu Rosu

\section{INTRODUCTION}

Ecotourism as a tourism form has its root back to the 1960's (Hetzer, 1965), but it becomes widespread and popular in the $21^{\text {th }}$ century. Because it's nature based tourism form, all touristic activities that consider natural environment a touristic potential and value belongs to ecotourism. Outdoor walking and hiking or so named "tourism on boots" are parts of ecotourism (Rodrigues et. al, 2010). Hiking involved activities are increasing and has become popular in the past decade (Lynn et al., 2003). Beside its importance in tourism, hiking as part of ecotourism could contribute to economic growth of the region where they are practiced (McNamara et al., 2011; Vodă et al., 2014).

Outdoor activities, like walking and hiking are practiced not only by young and sporty people, but all age group, as walking in nature has been proved to be a heath sustaining and regenerating activity (Hansmannn et al., 2007; Li et al., 2011). It's not only beneficial for health, but it could be important as a social activity too. It's normal that different age categories, people with different fitness level are practicing hiking together. In such cases the members of these mixed groups departs less or more from each other which can have negative consequences, the community experience suffers the external risk rises (attacks of wild animals, getting lost, etc.).

Our research has the goal to develop a methodology through which those locations where members of the same group but with different fitness level departs from each other. In such places the faster members of a group should wait the slower ones, and there resting places could be arranged.

Lacu-Rosu, the test area is a tourist resort in the middle of Romania, in the hearth of the Eastern Carpathians (figure 1), having a $25 \mathrm{~km}$ distance from Gheorgheni along the 12C national road which connects Transylvania to Moldova. It has a captivating lake, named Red Lake or Killer Lake surrounded with mountains and followed by a splendid gorge

\footnotetext{
${ }^{1}$ Babeș-Bolyai University, Faculty of Geography, 400006 Cluj-Napoca, Romania, zsmagyari@gmail.com;dombay.istvan@gmail.com
} 
along Bicaz river. The nature formed a breathtaking landscape (figure 1) with a varied relief, with narrow corridors and steep walls, dolinas, underground water systems, caves, uvalas, rock slides, etc. (Ciangă, 2001)

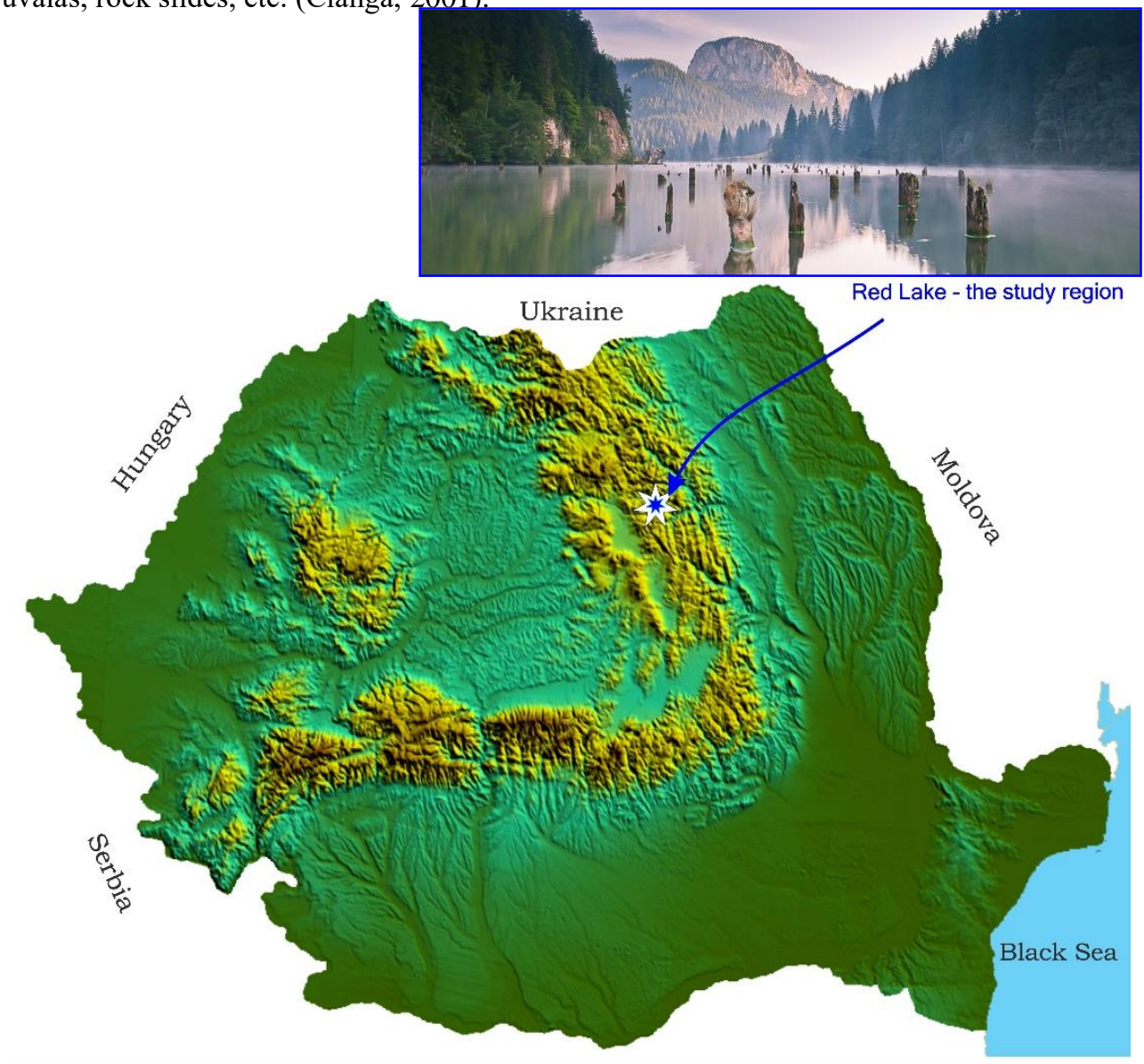

Bulgaria

Fig. 1. - Location of Red Lake region inside the Eastern Carpathians and its landscape with Little Suhard peak (source: http://www.patriotaeuropa.hu/kategoria/zold-vilag/8.html)

As described also by Orbán Balázs in 1871, there are a plenty of natural values (Licoș gully hole having over $50 \mathrm{~m}$ depth with permanent ice and snow formation; over 50 caves along the Bicaz river, etc.), protected flora (edelweiss - Leontopodium alpinum, yew tree Taxus baccata, globe flower - Trollius europaeus, Romer grass - Festuca idahoensis, etc.) and fauna (brown bear - Ursus arctos, Eurasian lynx - Lynx lynx, black woodpecker Dryocopus martius, etc.) which represents an excellent potential for ecotourism in general and for hiking in particular. 


\section{DATA AND METHODS}

Our study aims to develop a methodology for determining optimal resting places and to apply and test it on 5 of the most important and visited hiking trails in Lacu-Rosu region. The selected hiking trails are presented in figure 2 . We tried to choose trails with different characteristics (table 1) as our test to be more comprehensive.

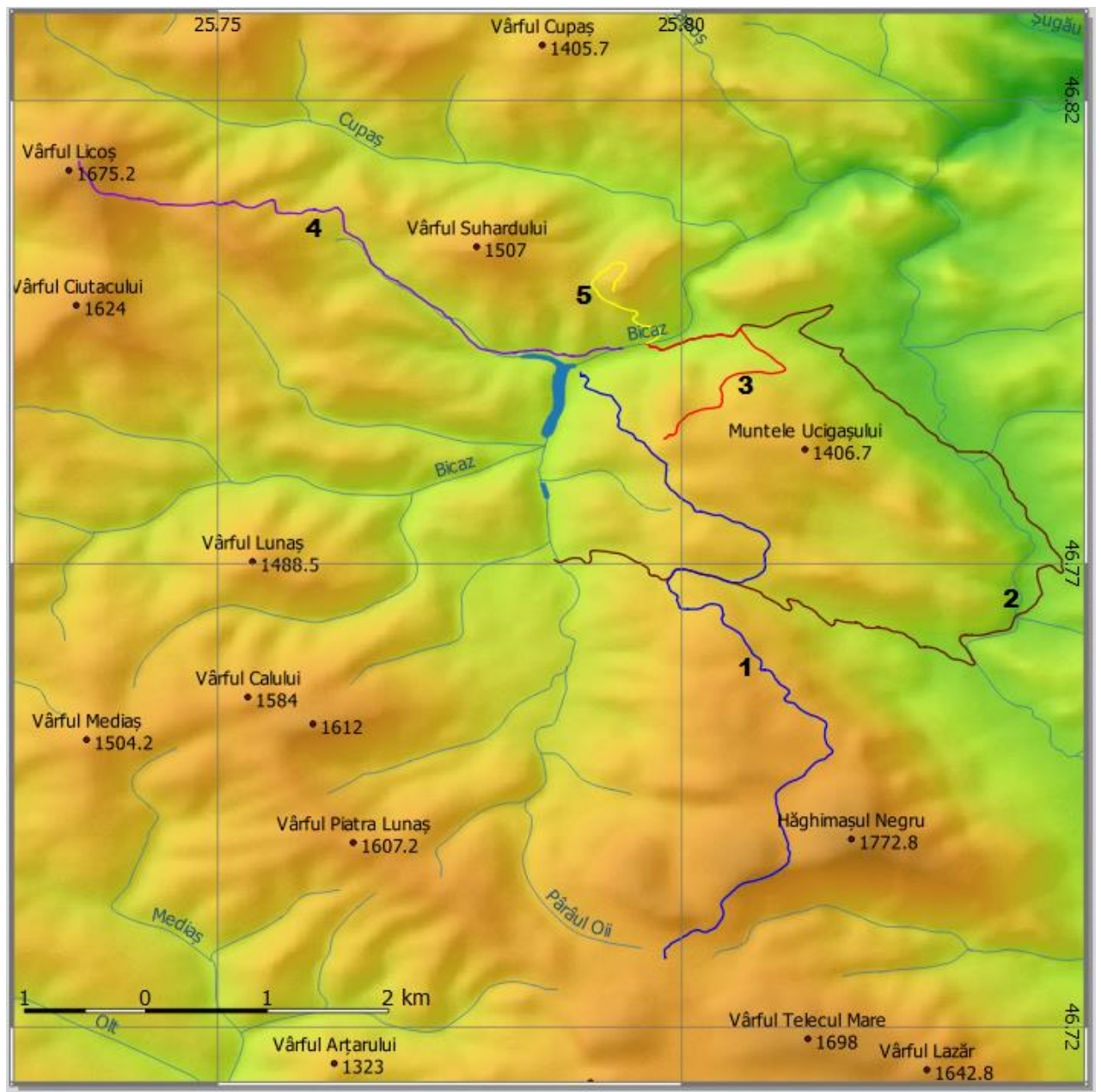

Fig. 2. - Location of the analyzed trails

1 - Lacu-Roșu (Red Lake) - Poiana Albă (White meadow)

2 -Lacu-Rosu (Red Lake) - Pârâul Oii (Sheep's creek)

3 - Lacu-Roșu (Red Lake) - Belvedere Lacu-Roșu (Lacu-Roșu viewpoint)

4 - Lacu-Roșu (Red Lake) - Licoș(Licoș gully hole)

5 - Lacu-Roșu (Red Lake) - Suhardu Mic (Little Suhard)

The base data of the research were the tracks of the tourist trails and the digital elevation model of the region. 
The digital elevation model was interpolated to $5 \mathrm{~m}$ resolution, based on contour lines digitized from topographic maps having a scale of 1:25000.

The tracks were obtained from the local mountain rescue team, which had the task to mark and maintained them. Before we can used the tracks in our research we had to preprocess them for two reasons. Once, due to the fact that the tracks were collected by handheld GPS they presented deviations of several meters against reality. The correction was made together with the rescue team personnel based on aerial photography. Secondly the distance between the successive vertices of the line feature representing the trail should be under the half of the digital elevation model's resolution for further precise computation. As the digital elevation model has $5 \mathrm{~m}$ resolution the distance between successive vertices has been placed to $1 \mathrm{~m}$.

Table 1. - Some quantitative characteristics of the analyzed trails

\begin{tabular}{|l|c|c|c|}
\hline No. & Length $[\mathrm{km}]$ & Naismith hiking time [hh:mm] & Total elevation difference [m] \\
\hline 1 & 12.4 & $5: 10$ & 1957 \\
\hline 2 & 13.3 & $5: 34$ & 1873 \\
\hline 3 & 3.4 & $1: 43$ & 630 \\
\hline 4 & 6.4 & $3: 17$ & 1133 \\
\hline 5 & 2.3 & $1: 24$ & 652 \\
\hline
\end{tabular}

In this research we considered that a resting places should appear whenever two persons departs from each other over a given t travel time. Time calculus has been made using Naismith rule (Naismith, 1892) with Langmuir completion (Langmuir, 1984) and Tranter's correction. To identify the most suitable locations in general, without knowing the hikers group members fitness, we made a comprehensive simulation including all possibilities. The fitness level were considered as described in Tranter correction for hiking time (fig. 3).

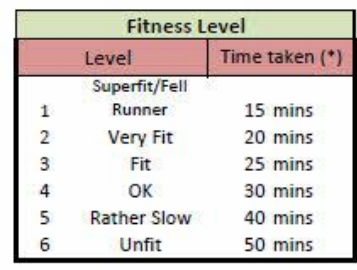

- climb $300 \mathrm{~m}$ in $800 \mathrm{~m}$ distance.

Fig. 3. - Tranter correction table (source: https://antondotreks.files.wordpress.com)

The algorithm for locating the resting points were the following:

* for every selected trail in current level:

* for every chosen fitness category pair:

* Naismith time with Tranter correction along the trail is calculated

* those locations are identified where the travel time between the two groups with different fitness level, exceeds a given value

* for every location a weight is associated which is the reciprocal difference between fitness classes

* the first $\mathrm{n}$ locations are selected in which's vicinity the weighted sum of locations are maximal 


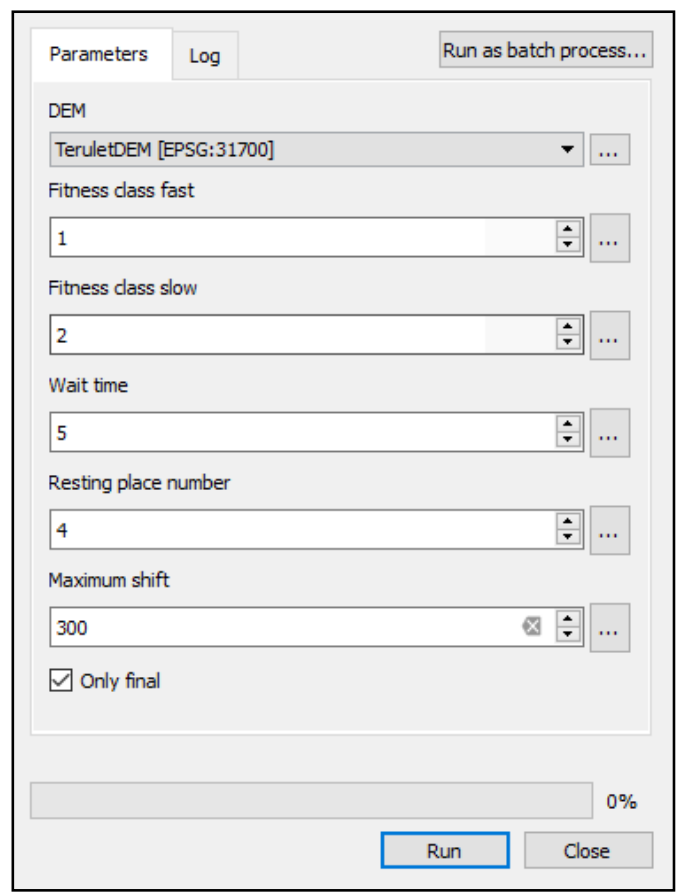

Fig. 4. - User interface for selecting parameters

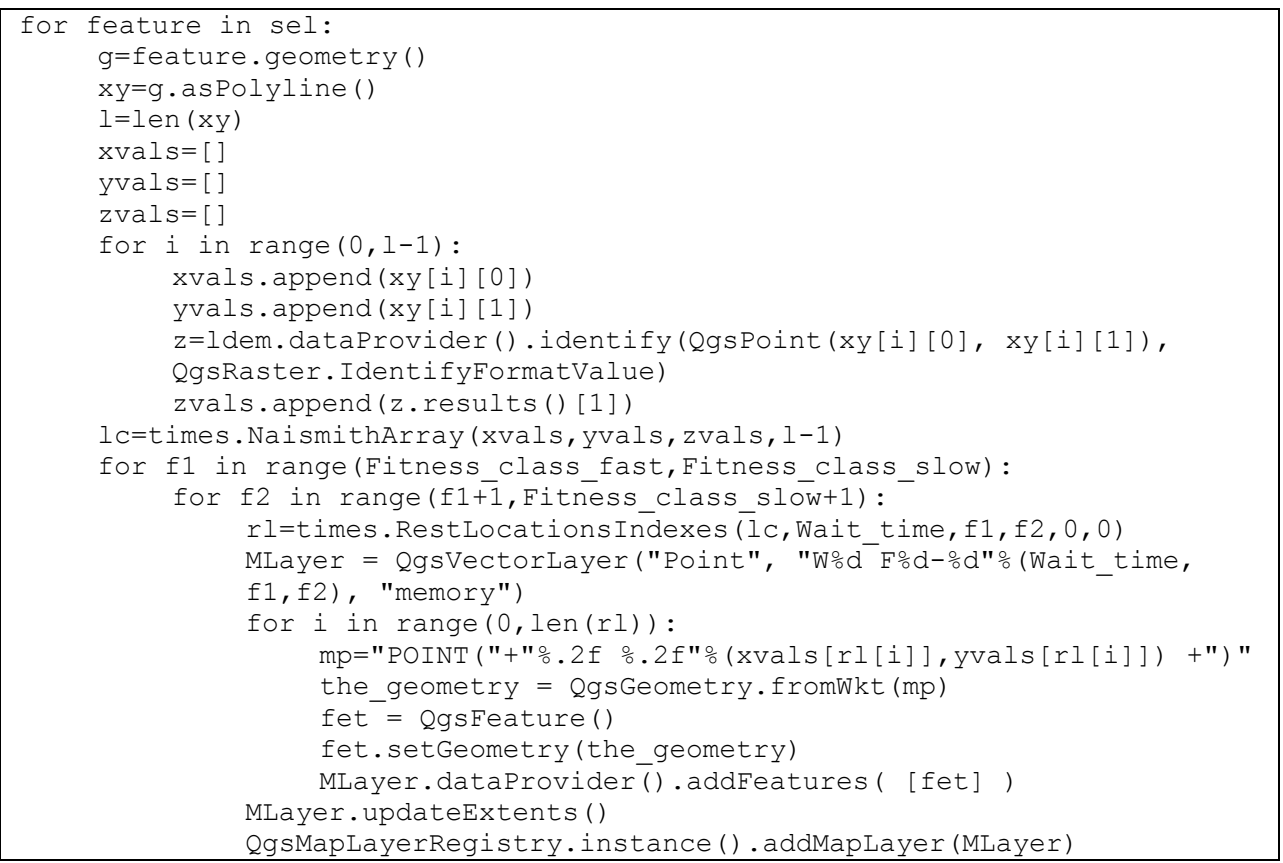

Fig. 5. - Python code for calculating and adding resting locations as new layer for different fitness level pairs 
The presented algorithm was implemented in Python (fig. 5) and used in QGIS, as QGIS natively supports Python programs. The implemented Python script can be parametrized with the followings (fig. 4):

- raster layer selection, containing the digital elevation model

- starting and ending fitness level between which every pair are considered

- waiting time

- number of desired resting location considering a weighted sum off all selected fitness pairs

- shift distance for a resting location, representing the maximal distance within relocation is possible. This parameter is used in combining different resting locations corresponding to different fitness levels

- checkbox to mark weather only the final (combined) resting places layer should be added to map composition or all resting places for every fitness level pair

The analysis is done for every selected line feature of the activated layer, or if no selection has been made then for all line features in the layer.

\section{RESULTS AND DISCUSSION}

The above mentioned Python program was applied to every of the 5 trails, for every pair of fitness class, considering a waiting time of 5 minutes. For trails 5 and 6 a person having fitness class of 6 could not go through the trail according to Tranter's correction. While it's normal that persons with distant fitness levels won't form a hiking group we observed that rising the fitness level with just a single, the resting place's number rises significantly (in many cases almost doubles) (fig. 6).
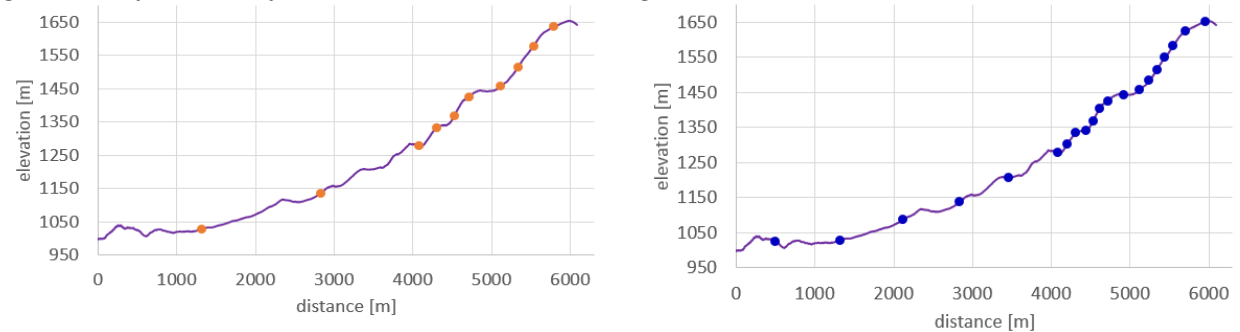

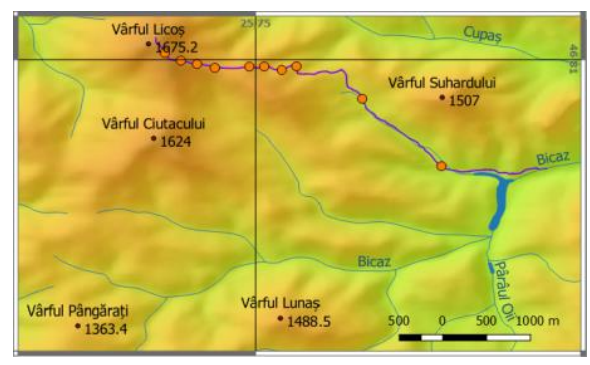

a) 1-2 fitness class pair

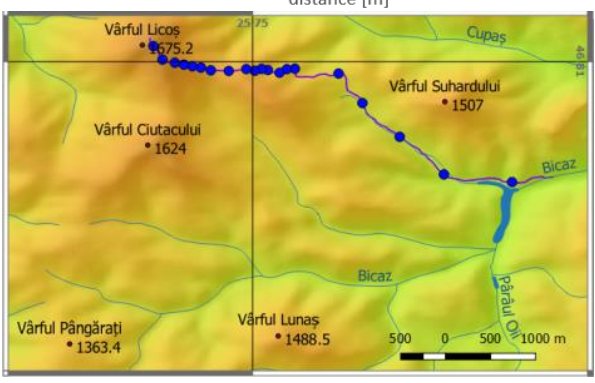

b) 1-3 fitness class pair

Fig. 6. - Optimal resting places for trail 4 - Lacu-Roșu (Red Lake) - Licoș(Licoș gully hole) - with 5 minute waiting time and different fitness level pairs 
Based on fitness level explanation in figure 3, we considered that most of the hikers will have fitness levels between 3 and 5. For 3-4 fitness level combination the optimal resting places location is shown in figure 7 . The obtained number of resting locations was considered the optimal number and was used in further phase of the analysis.

Although we considered that the most probable combination of a mixed tourist group has persons with 3 and 4 fitness level we want to consider all possibilities. As mentioned before different fitness level combinations has different probabilities. This probability value decreases as the difference between fitness levels pairs increases. Choosing an inverse value of this difference every determined location received this value as its weight to become a resting location.

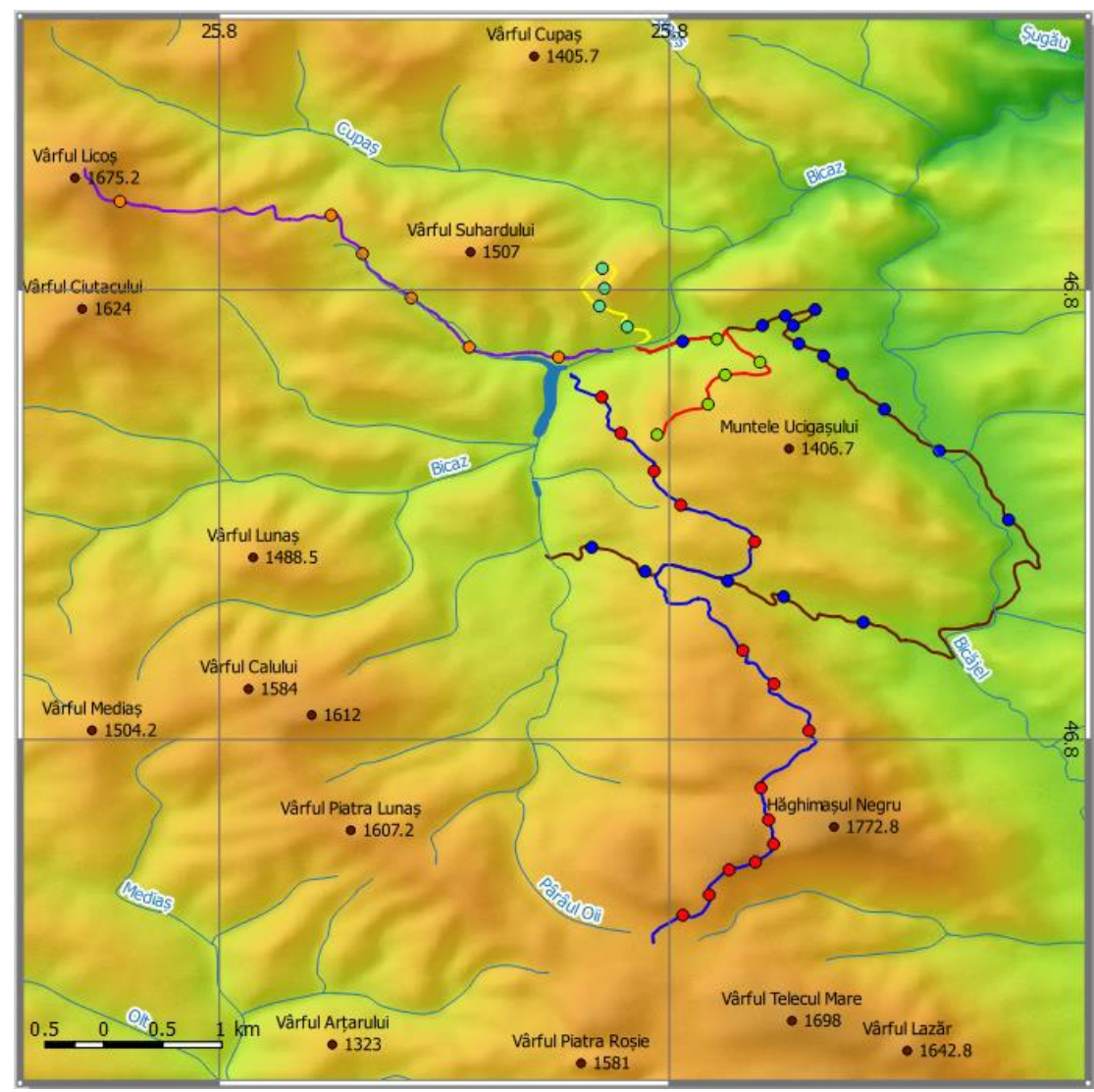

Fig. 7. - Optimal resting places for all trails with 5 minute for the most probable 3 and 4 fitness level pairs

Having a parameterized value of shift distance, we could configure the maximum distance within the weight value decreases to zero, a distance within a given resting location can be repositioned, gradually losing its weight with distance. We considered 3 shift distances: $\pm 150, \pm 300$ and \pm 500 meters. After combining the obtained weight values for all selected fitness pairs and selecting the highest values we obtained the optimal locations for resting places. 
We have modelled six scenarios: all fitness level pairs with $\pm 150, \pm 300$ and \pm 500 meters shift distance and 3 to 5 fitness level combinations with the same shift distance. The resulted resting locations were overlapped as shown if figure 8 . While different scenarios has different circle radius in representation it's easy to identify those locations which contains all six circles representing the most suitable places where arranged resting places could be built, eventually with benches and tables.
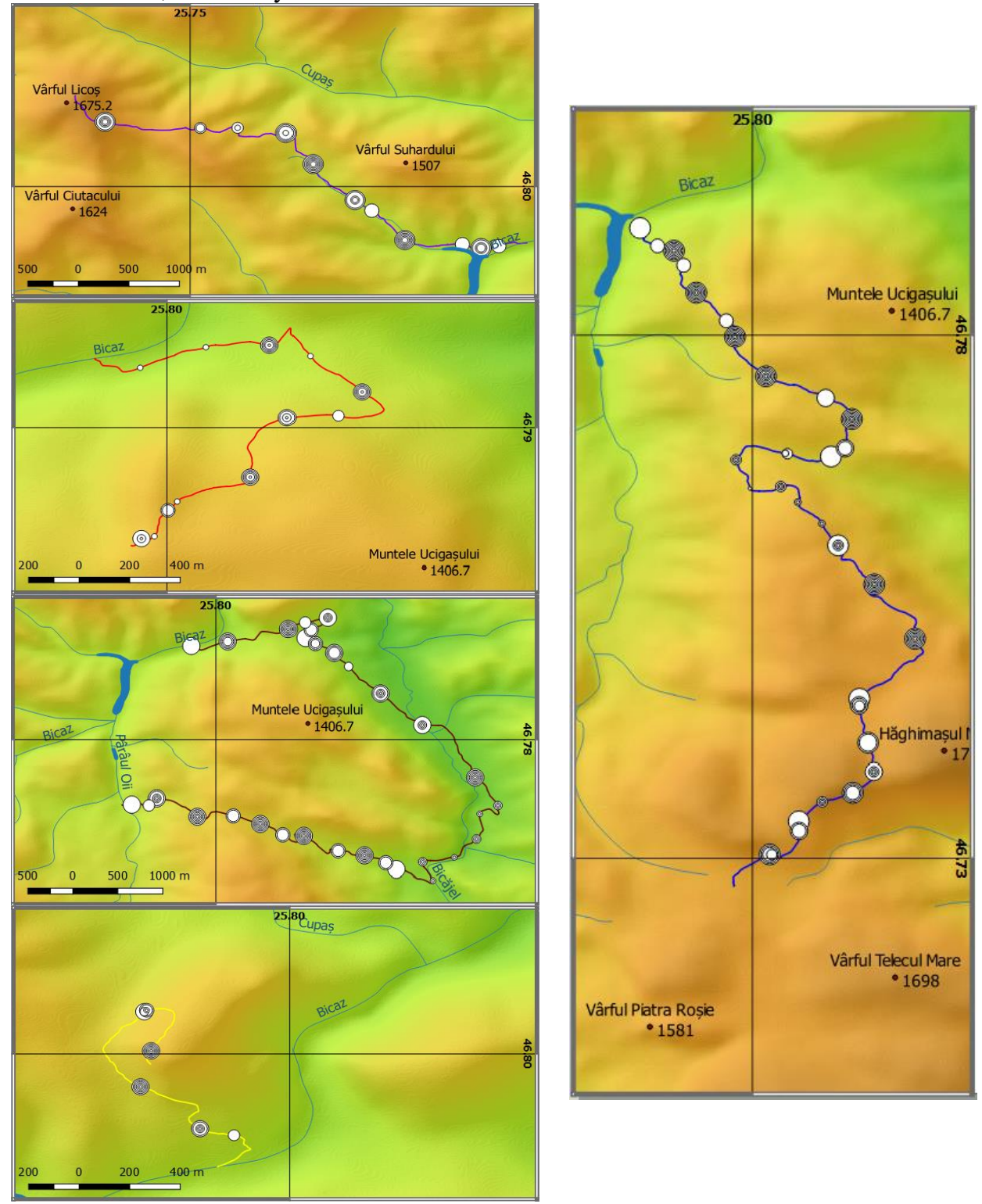

Fig. 8. - Optimal resting places taking account all fitness level pairs (more overlapping circles identifies more optimal locations) 


\section{CONCLUSIONS}

The purpose of the research was to search the optimal resting place for a mixed group tourist, where different persons have different fitness level. After the development of a proper localization algorithm and its implementation in Python and use in QGIS for five important but different length and hardness tourist trails in Lacu-Rosu region we can conclude that there are important location differences of resting places not only in case of distant fitness level pairs but also in case of adjacent fitness levels. The developed algorithm contains a possibility to refine the fitness level over the predefined values. The use of this possibility needs individual calibration for hikers which was not included in this research. The developed algorithm considers the total fatigue of tourists, without considering energy regeneration, but for 5 minutes of waiting time (time which was constantly used in analysis) it's useless. The existence of a parameterized analysis module offers a wide range of simulations and further analysis for other location with different characteristics and needs.

There are several locations in which or in which close vicinity the resting places concentrates for multiple fitness level pairs. These locations should be considered the most important ones for arranged resting places. The selected locations for resting places are based only on departure between persons. Surely for the proper location of resting places those locations should be searched around the determined points which by their touristic potential would increase the touristic experience.

\section{REFERENCES}

Ciangă, N. (2001), Romania. Tourism Geography I. (in Romanian), Cluj University Press, Cluj, Romania

Hansmann, R., Hug, S.-M., \& Seeland, K. (2007). Restoration and stress relief through physical Activities in forests and parks, Urban Forestry \& Urban Greening, 6, 213-225.

Hetzer, W. (1965), Environment. Tourism. Culture. Links, July 1-3

Langmuir, E. (1984), Mountaincraft and leadership, The Scottish Sports Council/MLIB Cordee, Leicester

Lynn, N. A., \& Brown, R. D. (2003). Effects of recreational use impacts on hiking experiences in natural areas, Landscape and Urban Planning, 64, 77-87. http://dx.doi.org/10.1016/S0169 2046(02)00202-5.

Li, Q., Otsuka, T.,Kobayashi, M., Wakayama, Y., Inagaki, H., Katsumata, M., et al. (2011). Acute effects of walking in forest environments on cardiovascular and metabolic parameters, European Journal of Applied Physiology, 111, 2845-2853

McNamara, K. E., \& Prideaux, B. (2011). Planning nature-based hiking trails in a tropical rainforest setting. Asia Pacific, Journal of Tourism Research, 16 (3), 289-305. http://dx.doi.org/10.1080/10941665.2011.572665

Naismith, W.W. (1892), Untitled. Scottisch Mountaineering Club Jurnal, 2, 135

Orbán, B. (1871), Description of Székelyföld (in Hungarian), Tettey Nándor and co., Pest, Hungary

Rodrigues, A., Kastenholz, E., \& Rodrigues, A. (2010). Hiking as a relevant wellness activity: results of an exploratory study of hiking tourists in Portugal applied to a rural tourism project. Journal of Vacation Marketing, 16, 331-343, http://dx.doi.org/10.1177/1356766710380886

Vodă, M., Moldovan, L., Torpan, A., Henning, A. (2014), Using GIS for mountain wild routes assessment in order to qualify them for tourism valorization, Geographia Technica, 9/1, 101-108 